\title{
Of Mice and Women: A Short History of Mouse Mammary Cancer Research with an Emphasis on the Paradigms Inspired by the Transplantation Method
}

\author{
Daniel Medina \\ Department of Molecular and Cellular Biology, Baylor College of Medicine, Houston, Texas 77030 \\ Correspondence: dmedina@bcm.edu
}

The ability to transplant mammary epithelial cells of any age or developmental stage to the normal anatomical site of an inbred recipient mouse strain has revolutionized the studies of mammary development and tumor biology over the past 50 years. This simple method has made the mammary gland of the rodent one of the most accessible and studied organs and facilitated our understanding of the fundamental cellular and molecular properties of normal and neoplastic development. This short review outlines the early concepts that led to the development of the transplantation technology and the impact of this method on our understanding for a variety of processes important both for the normal development and differentiation of the gland as well as the phenomena of neoplastic progression.

\begin{abstract}
The purpose of this short article is not to provide a comprehensive history of mammary cancer research in the 20th century but to highlight the origin of principles that our senior scientists take for granted, and to illustrate to the young investigators entering the field of breast cancer research the continuity and evolution of our current understanding of the origin and progression of mammary cancer. Ideas do not develop in thin air but are built upon the labor and thoughts of many scientists. It is to these scientists that this review is dedicated with respect, appreciation and acknowledgement. These early scientists are the giants who constructed the steps we must ascend to build the future. For individuals who want to read a
\end{abstract}

more comprehensive history of experimental mammary cancer, the recent article by Cardiff and Kenney provides a superb and thorough historical review (Cardiff and Kenny 2007).

\section{THE VERY BEGINNING}

The mouse mammary tumor system is one of the most extensively studied model systems available. The reasons for the extensive investigation are numerous and originate in 1910 when C.C. Little developed the first inbred mouse strain, the DBA strain. The major mouse strains that were developed in the subsequent 15 years by Little and his colleagues, such as L. Strong, are still actively used today and

Editors: Mina J. Bissell, Kornelia Polyak, and Jeffrey Rosen

Additional Perspectives on The Mammary Gland as an Experimental Model available at www.cshperspectives.org

Copyright (C) 2010 Cold Spring Harbor Laboratory Press; all rights reserved; doi: 10.1101/cshperspect.a004523

Cite this article as Cold Spring Harb Perspect Biol 2010;2:a004523 
D. Medina

include $\mathrm{C} 3 \mathrm{H}, \mathrm{BALB} / \mathrm{c}$, and $\mathrm{C} 57 \mathrm{BL}$ (Strong 1935). By 1966, there were over 213 inbred strains of mice (Staats 1966). Since then, the development of genetically engineered mice has allowed the investigator to examine the effects of specific genes on the development and progression of mammary tumors. The development of inbred strains introduced rigor and specificity to the study of the origin and pathology of mammary tumors. Before this time, the transplantability of mammary tumors was an unreliable event in the arsenal of the experimental biologists. Although there were tumor lines that were serially transplantable among mice, the unreliability of the method created a lot of uncertainty about the generality of the results. The reliability of inbred strains and the use of serial transplantation led to the pioneering studies of Leslie Foulds whose studies provided the basic tenets of mammary tumor progression (Foulds 1949, 1956). Second, the presence of inbred strains allowed the selection of mice with different incidences and types of cancers. Strains of mice were developed that were resistant (i.e., C57BL) as well as highly susceptible (i.e., $\mathrm{C} 3 \mathrm{H}, \mathrm{BALB} / \mathrm{c}$ ) to mammary cancer development. Strains such as $\mathrm{C} 3 \mathrm{H}$ and DBA had a high incidence $(>70 \%)$ of mammary tumors in virgin and breeding mice, whereas strains such as BALB/c and C57BL had a very low incidence even in breeding mice $(<5 \%)$. Third, the presence of inbred strains led to the pioneering studies of the etiology of mammary cancer, which focused on the interaction of the trilogy of factors: viral, hormonal, and genetic.

Before the development of inbred strains, there were pioneering works by Apolant (Apolant 1906) and Haaland (Haaland 1911) that provided the seminal observations on the pathobiology of mouse mammary cancer. These investigators described not only the epithelial origin of mammary cancers but also the gradations that existed between normal, hyperplastic, and neoplastic stages of the gland. These observations still guide us today as we have been filling in the blanks for the past 100 years. The development of inbred strains of high and low susceptibility to mammary cancer provided a more quantitative approach to the study of the pathobiology of mammary cancer. In 1938, Fekete (Fekete 1938) described areas of hyperplasia that appeared to directly progress to mammary cancer. In the same year, Gardner (Gardner et al. 1939) described different forms of hyperplastic lesions that involved either the ductal component or the alveolar component of the mammary tree and suggested that these lesions progressed to mammary cancers. A large number of investigators in the 1940s and 1950s provided similar and additional observations on the pathobiology of mammary cancer and emphasized the significance of these hyperplastic lesions in the development of mammary cancer (reviewed in Medina 1973a).

\section{THE TRILOGY OF MMTV, HORMONES, AND GENETICS}

\section{Hormones}

The demonstration of the importance of hormones for mouse mammary tumorigenesis stems from the clinical observation by Beatson (Beatson 1896) that removal of the ovaries from a human patient with breast cancer led to regression of the cancer. Lathrop and Loeb repeated the experiment in mice in 1916 (Lathrop and Loeb 1916) demonstrating that ovarian hormones were necessary for the development of mammary cancer. Later experiments showed that estrogens could replace ovarian hormones (Lacassagne 1932). In 1948, Bittner (Bittner 1948) coined the term "inherited hormonal influence" to explain the difference in mammary tumor incidence between $\mathrm{C} 3 \mathrm{H}$ and A virgin mice. Although both mice carry the milk borne MMTV, the former mice have a high tumor incidence in both virgin and breeding mice whereas the latter have a high tumor incidence in only the breeding mice. As the difference in tumorigenesis could not be attributed to differences in ovarian function, Bern and Nandi (Bern and Nandi 1961) suggested that the inherited hormonal influence was caused by differences in growth hormone levels. An extensive study by Singh (Singh et al. 1970) could not show conclusively the importance of growth hormone for the inherent differences 
in mammary tumor incidence in virgin mice. The authors concluded that the inherited hormone influence probably represented different combinations of hormones in different species.

The role of hormones is obligatory, although in many cases permissive. Bern and Nandi (Bern and Nandi 1961) emphasized that normal hormonal stimulation is necessary for the normal development of the mammary gland and also to provide the necessary cellular environment for an oncogenic agent to act. The hormones for mammogenesis and noduligenesis (i.e., induction of hyperplastic alveolar nodules) are similar (estrogen, luteoid or corticoid, prolactin, or growth hormone). However, once mammary tumors are formed, the tumors are estrogen independent. This is a general rule for mouse mammary tumors, although there are notable exceptions (Allred and Medina 2008). This situation contrasts sharply with mammary tumors in the rat and breast cancers in humans, a significant percentage of these tumors are estrogen-dependent for growth. The hormonal influence has been shown in other ways. Mammary tumor development is enhanced by pregnancy or by exposure to continuous levels of prolactin in low tumor incidence strains such as C3Hf (Muhlbock and Boot 1959). Conversely, lactation can inhibit tumor development (Fekete 1940). In the modern era, the role of hormones is still being investigated and exploited with studies focusing on the use of agents that block estrogen signaling (i.e., tamoxifen) to prevent tumor development or tumor growth (Medina et al. 2005).

\section{Mouse Mammary Tumor Virus (MMTV)}

With the advent of inbred mouse strains, several investigators (Lathrop and Loeb, MacDowall and Richter, Little, Korteweg, and Fekete) showed the presence of an extrachromosomal factor important for the high mammary tumor incidence in specific strains (reviewed in Oberling and Guerin 1954). This was shown by cross-breeding high incidence strains with low incidence strains with the result that the maternal parent determined the mammary tumor incidence. This led to the classic experiment by Bittner (Bittner 1936) that showed that the maternal influence was a factor transmitted by milk. This observation generated a new era in mammary cancer research with an emphasis on the role of a virus as an important etiological agent in mice. Subsequent studies showed that the transmitted factor was eliminated by foster nursing newborn pups of high incidence strains on low incidence mothers and conversely, foster nursing pups of low incidence strains on mothers of high incidence strains generated a high mammary tumor incidence (Nandi and McGrath 1973). The agent was infectious upon injection of the agent into susceptible hosts (Lyons and Moore 1965) and was an RNAvirus identified as a B particle (Dmochowski 1954; Pitelka et al. 1964). Multiple variants of the virus were isolated so MMTV represents a family of related viruses, identified by various names, but commonly as MMTV-S, MMTV-L, and MMTV-P (Nandi and McGrath 1973). Genetic studies showed the presence of endogenous integrated viruses in the genome, which can be transmitted by the germ line as well as through the milk. In addition, there are integrated virus sequences that are not replicated as an intact virus, except in rare instances where an endogenous sequence becomes activated and infectious. (Drohan et al. 1981).

With the discovery of MMTV activation of endogenous genes as the mechanism of the oncogenic effect of the virus (Nusse and Varmus 1982), the research on MMTV took two opposite directions. Several new insertion sites were discovered in different models of mouse mammary cancer and these were initially labeled as int-1, int-2 etc. Subsequent studies identified the gene contained in each of the insertion sites (Jhappan et al. 1992; Nusse et al. 1991). This in turn led to the development of new animal models, where specific genes identified as insertion sites, were overexpressed in the mammary gland to drive mammary tumorigenesis. However, extensive and sometimes contentious studies failed to identify a mammary tumor virus that was etiologically important in either the chemical carcinogen-induced rat mammary tumor model or in human breast cancer. The latter observation, which was buttressed by the 
D. Medina

failure to find activation of an int-1 (wnt-1) homolog in human breast cancer dampened enthusiasm for extensive studies on MMTV. The virus remained as a useful tool in genetic engineering of expression of oncogenes because of the hormonal regulation of the MMTV-LTR (Cardiff and Kenny 2007).

\section{Genetics}

It is perhaps ironic that the first major factor implicated in the genesis of mammary tumors is today the least understood mechanistically. The development of inbred mouse strains quickly established the presence of high and low susceptible strains of mammary tumorigenesis. While early studies implicated the mammary tumor virus as one contribution to high tumorigenesis, it was clear that there were strains that were intrinsically resistant to mammary tumorigenesis. Several mechanisms have been proposed. First, several alleles identified between the years 1940 and 1965; namely the agouti, brown, obese, have been associated with increased susceptibility (Nandi and McGrath 1973). The cellular and molecular mechanisms governed by these genes have not been elucidated. Second, transplantation studies in hybrid mice by Dux and Muhlbock (Dux and Muhlbock 1966) and Mintz (Mintz 1970) suggested that genetic differences in susceptibility were determined at the mammary cell level. Third, recent studies using genetically engineered mice have started to identify additional genetic loci that confer susceptibility. The host genetic background has a profound effect on mammary tumorigenesis upon deletion of a single gene, such as p53 (Kuperwasser et al. 2000). Deletion of the p53 gene in BALB/c background results in mammary tumorigenesis whereas deletion of the same gene in a C57BL background has no effect on mammary tumorigenesis. Examining F1 and F2 backcrosses of the $\mathrm{BALB} / \mathrm{c}$ and $\mathrm{C} 57 \mathrm{BL} / 6$ strains, Koch et al. (Koch et al. 2007) were able to identify two modifier loci for susceptibility to mammary tumorigenesis. These two loci were named $\mathrm{mtsm} 1$ and mtsm2. Additionally, using a similar approach, DMBT1 was identified as another candidate modifier of breast cancer risk (Blackburn et al. 2007). This type of approach will provide the information that will allow one to finally understand the basis for genetic-determined susceptibility to mammary tumorigenesis, an area that first surfaced over 100 years ago.

\section{ENVIRONMENTAL CARCINOGENS}

The use of chemical carcinogens to induce mammary tumors in mice also has a long history, dating back to 1949 (reviewed in Medina 2000a). The most frequently used chemical carcinogens were 3-methylcholanthrene, 7,12dimethylbenzanthracene, and urethane with the alkylating agents, methylnitrosourea and ethylnitrosourea also used in some studies. DMBA is the most potent of the three carcinogens but the response of mice is very much strain dependent with DBA2f and Sencar mice being the most sensitive and C57BL/ 6 being the least sensitive. Two of the limitations using mouse models have been the need to use multiple doses and the concurrent induction of other tumor types, notably leukemias, lung, stomach, and ovarian tumors, which can approximate $25 \%$ over the 12 mo assay period. In Sencar mice, lowering the dose of the carcinogen can result in a markedly lower incidence of secondary tumors and still retain a high incidence of mammary tumors (Qing et al. 1997). The optimal agent may be ethylnitrosourea as it is effective with a single dose and induces only adenocarcinomas. The other chemical carcinogens often induce adenosquamous carcinomas as well as adenocarcinomas. Concomitant hormone stimulation of the carcinogen-treated mammary gland markedly enhances mammary tumorigenesis, increasing overall tumor incidence and significantly lowering the mean tumor latent period. Exogenous hormone stimulation is obligatory for the rapid induction of carcinogen-altered cells and facilitates the expression of carcinogen-altered cells into neoplastic cells in $\mathrm{BALB} / \mathrm{c}$ mice. Progesterone is the critical hormone as shown in several studies using ovariectomized mice (Jull 1954) and transgenic mice (Lydon et al. 1999). 
The possible interaction between MMTV and chemical carcinogens has been studied extensively. In four separate studies, chemical carcinogen-induced mammary tumors had the same levels of MMTV DNA, RNA, and protein (gp52) as homologous normal mammary glands. These studies were done in $\mathrm{C} 3 \mathrm{H} / \mathrm{StWi}$ (Smith et al. 1978), BALB/c, and BALB/cfC3H (Swartz-Dusing et al. 1979), (C57BL x DBA/ 2f)FI (Medina et al. 1980), and BALB/c, 020, and C3Hf mice (Michalides et al. 1978). The spontaneous tumor incidence of these studies ranged from $1 \%(\mathrm{C} 3 \mathrm{H} / \mathrm{StWi}, \mathrm{BALB} / \mathrm{c}$, [C57BL $x D B A / 2 f] F 1)$ to $35 \%$ (C3Hf/He, $020)$ to $90 \%(\mathrm{BALB} / \mathrm{cfC} 3 \mathrm{H})$. These results would indicate that persistent high levels of MMTV RNA and viral protein synthesis are not necessary for the maintenance of the neoplastic phenotype and suggest that chemical carcinogens do not activate the MMTV genome. If MMTV RNA is activated, then the activation is either transient or only a portion of the genome is activated, and that portion was not detectable by the probes.

Chemical carcinogen-induced molecular changes in the mouse mammary gland have not been extensively studied. A few studies have shown that DMBA and MNU result in Ha-ras and Ki-ras activation, respectively (Swanson et al. 1996; Kumar et al. 1990); in contrast, the tumor suppressor gene p53 is infrequently mutated in BALB/c mice (Jerry et al. 1994). Interestingly, p53 mutations are frequent in spontaneous tumors in BALB/c mice (Jerry et al. 1993). In recent years, there has been a lack of studies examining the mechanism of chemical carcinogenesis of the mouse mammary gland, which perhaps is because of the inability to show that chemical carcinogens found in the environment are a significant etiological agent for human breast cancer.

Irradiation-induces mammary cancer in mice at low incidence and a long latent period. $2 \mathrm{~Gy}$ of $y$-irradiation or acute neutron irradiation increased mammary tumor incidence (20\% each versus $7 \%$ ) in BALB/c female mice, whereas chronic neutron irradiation $(0.1 \mathrm{~Gy} / \mathrm{d})$. induced a $45 \%$ incidence of mammary tumors in BALB/c mice (Ullrich et al. 1977). Mammary tumors induced by radiation in BALB/c mice exhibit elevated levels of chromosome instability, a feature not found in chemical carcinogen-induced mouse mammary tumors (Ponnaiya et al. 1997). Like chemical carcinogen-treated mice, irradiated mice also exhibit ductal hyperplasias (Ethier and Ullrich 1982). The tumors induced by irradiation are typical mammary adenocarcinomas, ovarianindependent but highly metastatic to lung (reviewed in Medina 1982). Irradiation (4Gy) administered to BALB/c mice bearing preneoplastic nodule outgrowth lines enhanced significantly their tumor-producing capabilities, independent of p53 status (Medina et al. 1998). Additionally, studies have shown the importance and mechanism of off-target effects of irradiation in mammary tumorigenesis (Barcellos-Hoff and Ravani 2000). These characteristics of the irradiated mouse mammary gland provide a relevant model for human breast cancer induced by radiation, which is the only well documented environmental human breast carcinogen.

\section{PATHOBIOLOGY OF MAMMARY TUMORIGENESIS}

Two areas that have engaged the attention of mammary researchers for the past 100 years have been (1) the regulation of normal development of the mammary gland with an emphasis on the role of hormones and growth factors, and (2) the development of tumors with an emphasis on heterogeneity of tumor pathology, tumor progression, and the significance of preneoplasia. With the development of inbred strains and then the recognition of the different variants of the mammary tumor virus, it was recognized that the morphological characteristics of the mammary tumors that appeared in the different strains were markedly heterogeneous. Although these differences were recognized in the first 50 years, the first systematic categorization was performed by Dunn (Dunn 1946) with subsequent extensions by van $\mathrm{Nie}$ (van Nie 1967) and Sass and Dunn (Sass and Dunn 1979). Mouse mammary tumors were divided into three types: (1) the vast majority were 
D. Medina

carcinomas with subtypes A, B, C, Y, L, and P. These were seen in MMTV-infected mice, hormonally induced tumors and those that arose spontaneously in aged mice of lowtumor-incidence strains; (2) carcinomas with squamous cell differentiation commonly seen in chemical carcinogen-treated mice and more recently, in some genetically engineered strains, and (3) carcinosarcomas, also referred to as mesenchymal tumors, which are seen often in genetically engineered mouse strains. See (Medina 1982) for a detailed discussion of the specific cytomorphology of these subtypes. The mammary tumors that appear in some genetically engineered strains are generally carcinomas with cytomorphology sometimes indicative of the gene altered in the mouse (Cardiff et al. 1991). For instance, the cytomorphology of mammary tumors appearing in the c-neu transgenic mouse are extremely uniform with the tumor composed of cells that are pale and intermediate in size, whereas the tumors appearing in c-myc mice were composed of basophilic large cells. In contrast, mammary tumors appearing in the p53 null mouse are very heterogeneous and include classical carcinomas, carcinomas with extensive squamous development, and mesenchymal tumors.

Studies of mammary tumors have provided a rich literature on the patterns of change that occur with neoplastic growth and recurrence. This process was formulated and systematically developed in mammary tumors by Foulds (Foulds 1949) based on his studies in (RIII x C567Bl/6)F1 mice and finalized in his books on tumor progression (Foulds 1969). He concluded that the process of progression in mammary tumors followed several general patterns. Basically, progression occurs independently in different tumors in the same mouse and independently in different properties in the same tumor. Importantly, progression occurred independent of growth (i.e., can occur in latent cells), and is independent of size or age of the tumor. Progression can follow alternative paths of development and does not always reach an endpoint within the lifetime of the host. These general principals are valid today and help explain the biological behavior of tumors.
Studies since Foulds time have provided a genetic explanation for progression in terms of genetic instability driving progression and identification of specific genes that are the basis for some of the differences in growth and migration properties of cancer cells that recur with time. The role of cancer stem cells in progression has not been carefully addressed although there have been recent articles that have alluded to this issue (Polyak 2007).

The early studies (Apolant 1906; Haaland 1911) emphasized the presence of hyperplastic lesions in the mammary gland. The widespread use of inbred strains of mice allowed the comparison of hyperplastic structures in high and low mammary cancer strains. A large number of investigators (reviewed in Medina, 1973a) described hyperplastic structures in numerous strains, including $\mathrm{A}, \mathrm{BALB} / \mathrm{c}, \mathrm{BALB} / \mathrm{cfC} 3 \mathrm{H}$, $\mathrm{C} 3 \mathrm{H}, \mathrm{C} 3 \mathrm{Hf}, \mathrm{DBA}, \mathrm{I}, \mathrm{RIII}$, and their hybrids. These mice were either infected with any of the MMTV variants or virus-free and treated with prolonged hormonal stimulation or chemical carcinogens. These lesions were most frequently the more abundant alveolar hyperplasias (termed hyperplastic alveolar noduleHAN). However, other types of hyperplastic lesions were noted. Plaques are found in several mouse strains, such as RIII, GR and DD (Foulds 1956; Squartini and Severi 1962; Muhlbock 1965). These lesions are pregnancy dependent lesions that will progress to pregnancy-independent growths upon recurrence or serial transplantation. Keratinizing nodules (also termed inflammatory nodules) were seen in aged BALB/c mice or chemical carcinogen-treated mice but rarely give rise to tumors (Huesby and Bittner 1946; Medina 1976). Finally, ductal hyperplasias were the predominate lesion found in chemical carcinogen-treated mice (Jull 1954; Bonser 1956; Faulkin 1966). These lesions were of interest because they showed histologic similarity to premalignant lesions in the human breast.

By the late-1950s, the number of investigators involved in mammary tumor biology was small and located in several research centers throughout the world. In the United States there were active groups at National 
Cancer Institute (Walt Heston and Harold Andervont); in New York at the Rockefeller Institute (Dan Moore); and in Houston, Texas at the MD Anderson Institute (Leon Dmochowski) and Baylor College of Medicine (Robert and Annabelle Liebelt). In Europe, there were investigators in Italy (led by Francisco Squartini) and Amsterdam (led by Otto Muhlbock). In addition, some of the scientists active in the 1930s and 1940s were still active such as Bittner, Heston and Murray. The field had progressed from the establishment of inbred mice which allowed the systematic study of mammary cancer development to an extensive documentation of the biology and pathobiology of the disease in mice. What was needed was a way to manipulate the system which would allow functional studies. This method was provided in 1959.

\section{THE REVOLUTION INSPIRED BY TRANSPLANTATION}

In 1959, a seminal paper was published by DeOme and coworkers that revolutionized the study of mammary tumors (DeOme et al. 1959). These investigators were very knowledgeable about the normal development of the mammary gland and recognized that the majority of ductal growth took place in the mammary fat pad after 3 wk of age. They surgically removed the area of the mammary fat pad (@20\%) containing the mammary epithelial ducts in weanling mice (22-25 d of age). They observed that the fad pad did not contain any additional epithelial-lined ducts as the mouse matured and that they could transplant duct fragments (@1 mm) into the gland-free fat pad which expanded to fill the fat pad and would exhibit normal differentiation upon a hormonal stimulus. This act of transplantation could be serially repeated for a limited number of times with the same result. Additionally, they showed that transplants of hyperplastic lesions and tumors into the fat pad of syngeneic mice faithfully replicated their phenotype. In a short number of years, they showed by the transplantation method that the hyperplastic lesions were direct precursors to invasive mammary cancers. The initial experiments were performed on MMTV-positive $\mathrm{C} 3 \mathrm{H}$ mice. The hyperplastic lesions were morphologically similar to an enlarged alveolar lobule characteristic of pregnant mice, but had different hormonal dependencies than normal mammary epithelial cells as they were often found in virgin mice (Medina 1973a). The typical lesion was termed a hyperplastic alveolar nodule (HAN). The HAN were different from palpable mammary adenocarinomas not only in their well-differentiated morphology but also in essential biological properties. For example, HAN transplanted subcutaneously would be viable but would not expand in size, whereas tumors would grow progressively and metastasize to the lungs of recipient mice. A second fundamental property was the inability of HAN cells to overgrow normal mammary ducts in the fat pad. In contrast, mammary tumors would grow into the space occupied by normal ducts (Faulkin and DeOme 1960). Although early attempts to define a mechanistic explanation for this difference in growth behavior were pursued (Nicoll 1965), there is still a complete lack of understanding of the cellular and molecular mechanisms for these differences in growth behavior. Finally, the experiments of Daniel and coworkers showed that the normal mammary epithelial cell senesced upon serial transplantation (Daniel et al. 1968), whereas the hyperplastic lesions were immortal (Daniel, et al. 1975). Daniel and coworkers showed that the replicative senescence exhibited by normal mammary cells was a function of number of cell divisions undergone by the normal mammary cells (Daniel 1972). Interestingly, the replicative potential of normal mammary cells was the same whether the cells were originally derived from 3-wk-old virgin mice, 24-mo-old virgin mice, or 12mo-old multiparous mice (Young et al. 1971). The implications of these results for the current theory of mammary stem cells is important as they imply that stem cells are a relatively quiescent population until called upon to undergo expansion to repopulate the mammary fat pad, e.g., transplantation onto a cleared fat pad or perhaps in response to a wide-spread damage.

The ability to transplant different developmental stages of mammary epithelial cells both 
D. Medina

$$
\text { Normal } \rightarrow \text { Hyperplasia (HAN) } \rightarrow \text { Neoplasia }
$$

Figure 1. Initial multistep model of mammary tumorigenesis.

as initial populations and as serially transplanted populations led DeOme and his colleagues to propose the multistep model of mouse mammary tumorigenesis (DeOme 1967) (Fig. 1).

This model proposed that normal cells first developed into hyperplasias, which were immortal and nonobligate precursors of invasive cancers. These lesions were referred to as mammary preneoplastic lesions and had growth properties distinctive from invasive neoplasias (Medina 2000b). Subsequent experiments used mammary hyperplastic lesions that were MMTV-negative and developed either as a result of prolonged hormonal stimulation (Medina et al. 1970), chemical carcinogens (Medina 1973b), passage in cell culture (Kittrell et al. 1992), or from specific transgenic mice (Jerry et al. 2000; Medina et al. 2002; Maglione et al. 2004). Multiple experiments using the basic transplantation method showed that all of the hyperplastic lesions, whether they were of alveolar or ductal morphology, exhibited an increased potential for progressing to cancers compared with normal virgin mammary epithelial cells, that the lesions were immortal, that the rate of progression could be promoted by exposure to hormones or chemical carcinogens or infection by MMTV, and that molecular changes accumulated with progression that were specific for each stage (Medina 2002). Thus, the very earliest molecular changes occurred in regulation of the cell cycle, specifically alterations in the expression of cell-cycle genes. Limited studies using microarray approaches indicate there are numerous molecular changes occurring at the earliest preneoplastic stage (Namba et al. 2004). A current scheme of the multistage model of mammary development is shown in Figure 2 and illustrates that there is both linear and branched progression from normal to preneoplasia to neoplasia. Recent studies on human DCIS (Allred et al. 2008) suggest a similar set of patterns where DCIS progresses both in a linear fashion (i.e., low grade or high grade DCIS to invasive breast cancer) and in a branched fashion (i.e., low grade DCIS to high grade DCIS to invasive breast cancer).

The transplantation technique has become a standard method in the armamentarium of the mammary biologist and instrumental in experimental designs testing a wide variety of questions in normal mammary development as well as in mammary tumor biology: such as, the role of mammary stem cells; the intrinsic versus systemic role of specific genes dissecting the relative contributions of the stroma microenvironment to mammary tumorigenesis; and developing human in mouse (HIM) xenografts. For instance, the current experimentation on mammary stem cells depends heavily on limiting dilution experiments using injection into the cleared mammary fat pad (Shackleton et al. 2006; Moraes et al. 2007; Zhang et al. 2008). Elegant experiments (Jerry et al. 2000) showed that p53 deletion in only the mammary epithelial cells and not the mammary stroma was sufficient to confer the mammary tumorigenic phenotype. Similarly, other sophisitcated experiments (Mallepell et al. 2006) resolved a controversial role of ER $a$ in mammary cell

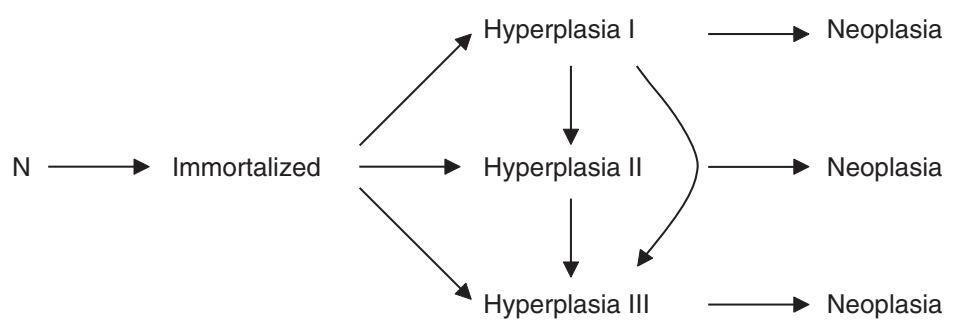

Figure 2. Multistage model of mammary tumorigenesis showing linear and branched progression. 
function by showing definitively that ER $a$ in the mammary epithelial cell and not in the mammary stroma was obligatory for estrogen signaling. Conversely, the importance of radiationinduced activation of TGFB in the stroma was shown to be critical for radiation-induced tumorigenesis of mammary preneoplastic cells (Barcellos-Hoff and Ravini 2000). The recent development of the HIM xenograft model for studying progression of human breast disease is based on the transplantation model (Kuperwasser et al. 2004). Most recently, a modification of the typical transplantation method is the intraductal injection of cells into the primary ducts, which also provides a different approach to growing and assessing functionally the growth and properties of human breast lesions (Behbod et al. 2009).

\section{THE EVOLUTION OF MAMMARY CANCER RESEARCH}

In the past 30 years, mammary cancer research has evolved along the path of cancer research in general. The roles of specific genes, such as hormone receptors, growth factors, cell cycle genes, transcription factors, signaling pathways have provided a picture of cell function at the molecular level for both the normal mammary cell and the neoplastic cell. The use of inbred mouse strains has evolved with the development of genetically engineered mouse strains in which a specific gene has been either over-expressed or deleted to allow the assessment of a specific gene on mammary tumorigenesis. Such genetically engineered mouse strains have evolved from germ line transmitted genes to conditional tissue-expressed genes so that gene function can be assessed as a function of development of the gland. In vitro culture systems have evolved from simple cell growth on plastic surfaces to growth in three dimensional systems that allows one to assess the effect of stroma constituents on the growth and invasion of epithelial cells. Imaging systems have been developed so the growth of a tumor can be assessed in live time. Molecular methods have been developed so that entire gene expression of a cell can be determined during different stages of development. Proteomic signatures of mouse blood before and during tumorigenesis can be evaluated to determine surrogate markers useful for detection and prevention. Finally, the advances in understanding of the development of human breast cancer provide a means to assess the significance of the patterns of mammary tumor development that are observed in different mouse models. Without inbred mouse strains and the unique transplantation methodology available to mammary tumor biologists, we would not have a sophisticated understanding of mammary tumorigenesis nor make the expected progress in preventing human breast cancer.

\section{THE HUMAN CONNECTION}

If we are to eliminate breast cancer as a major disease, we have to understand the causes of the disease, the development and progression at the cellular and molecular level, the alterations in genes, gene expression and protein function, and the susceptibility of cancer cells. The mouse models provide one means not only to understand the basic processes of breast cancer development but also the means to test potential preventive and curative agents. As we develop mouse models that more accurately reflect what is seen in the human breast cancer, then the power of the models becomes greater. For instance, research into specific altered pathways (ER-negative tumors, tumors containing mutated p53 tumor suppressor gene or c-myc amplification) will likely lead to the identification of specific therapeutic targets. Likewise, as we develop premalignant lesions that bear similarities to human premalignant lesions, we will be able to develop the means to prevent the progression of these lesions. Similarly, the development of HIM models will allow a more accurate assessment of the growth and progression of the disease. Human breast cancer is a complex disease that has many forms. It is characterized by morphological heterogeneity at the premalignant and malignant stages, by genetic instability that drives progression, by both ER-positive and ER-negative disease, by defined genetic changes, and by metastases to multiple organs (brain, 


\section{Medina}

bone, lung, liver, adrenal). The models that we currently have and will develop in the future need to replicate some of these essential features of the disease if we are to use these models to answer essential questions of human breast cancer.

\section{REFERENCES}

Allred DC, Medina D. 2008. The relevance of mouse models to understand the development and progression of human breast cancer. J Mammary Gland Biol Neoplasia 13: $279-288$.

Allred DC, Wu Y, Mao S, Nagtegael ID, Lee S, Perou CM, Mohsin SK, O'Connell P, Tsimelzon A, Medina D. 2008. Ductal carcinoma in situ and the emergence of diversity during breast cancer evolution. Clin Cancer Res 14: $370-378$.

Apolant H. 1906. Die epithelialen geschwulste des maus. Arbeiten Koniglchn Ins Exp The Zu Frankfurt 1: 7-68.

Barcellos-Hoff MH, Ravani SA. 2000. Irradiated mammary gland stroma promotes the expression of tumorigenic potential by unirradiated epithelial cells. Cancer Res 60: $1254-60$.

Beatson GT. 1896. On the treatment of inoperable cases of carcinoma of the mamma: Suggestions for a new method of treatment, with illustrated cases. Lancet 2: 104-107 and $162-165$.

Behbod F, Kittrell FS, Edwards D, Lamarca H, Kerbawy S, Allred DC, Polyak K, Rosen JM, Medina D. 2009. Intraductal transplantation mimics subtypes of human ductal carcinoma in situ. Breast Cancer Res 11: R66.

Bern HA, Nandi S. 1961. Recent studies on the hormonal influence in mouse mammary tumorigenesis. Prog Expt Tumor Res 2: 91-145.

Bittner JJ. 1936. Some possible effects of nursing on the mammary gland tumor incidence in mice. Science 84: 162.

Bittner JJ. 1948. Some enigmas associated with the genesis of mammary cancers in mice. Cancer Res 8: 625-639.

Blackburn AC, Hill LZ, Roberts AL, Wang J, Aud D, Jung J, Nikolcheva T, Allard J, Peltz G, Otis CN, et al. 2007. Genetic mapping in mice identifies DMBT1 as a candidate modifier of mammary tumors and breast cancer risk. Am J Path 170: 2030-2041.

Bonser GM. 1956. The significance of morphological changes in the mouse breast during chemical carcinogenesis. Acta Un Int Contra Cancer 12: 558-565.

Cardiff RD, Kenny N. 2007. Mouse mammary tumor biology: A short history. Adv Cancer Research 98: 53-116.

Cardiff RD, Sinn E, Muller W, Leder P. 1991. Transgenic oncogene mice. Tumor phenotype predicts genotype. Am J Pathol 139: 495-501.

Daniel CW. 1972. Aging of cells during serial propagation in vivo. Adv Gerontological Res (ed. B.J. Strehler), Vol. 4, 167-199. Academic Press, New York.

Daniel CW, Aidells BD, Medina D, Faulkin LJ Jr. 1975. Unlimited division potential of precancerous mouse mammary cells after spontaneous or carcinogen-induced transformation. Proc FASEB 34: 64-67.

Daniel CW, DeOme KB, Young LJT, Blair PB, Faulkin LJ Jr. 1968. The in vivo life span of normal and preneoplastic mouse mammary glands: A serial transplantation study. Proc Natl Acad Sci 61: 53-60.

DeOme KB. 1967. The mouse mammary tumor system. In Proceedings of the Fifth Berkeley Symposium on Mathematical Statistics and Probability (ed. J. Neyman), pp. 649-657. University of California Press, Berkeley, CA.

DeOme KB, Faulkin LJ Jr, Bern HA, Blair PB. 1959. Development of mammary tumors from hyperplastic alveolar nodules transplanted into gland-free mammary fat pads. Cancer Res 19: 515-520.

Dmochowski L. 1954. Mouse mammary tumor virus. J Natl Cancer Inst 15: 785-789.

Drohan W, Teramoto YA, Medina D, Schlom J. 1981. Isolation and characterization of a new mouse mammary tumor virus variant from BALB/c mice. Virology 114: $175-186$.

Dunn TB. 1946. Morphology of mammary tumors in mice. In The Pathophysiology of Cancer (ed. F. Homburger), pp. 38-84. Hoeber, New York.

Dusing-Swartz S, Medina D, Butel JS, Socher SH. 1979. Mouse mammary tumor virus genome expression in chemical carcinogen-induced mammary tumors in low- and high-tumor-incidence mouse strains. Proc Natl Acad Sci USA 76: 5360-5364.

Dux A, Muhlbock O. 1966. Tumor incidence in mammary glands transplanted from strains $\mathrm{C} 3 \mathrm{H}$ and 020 into their mammectomized F1 hybrids. Int J Cancer 1: 5-17.

Ethier SP, Ullrich RL. 1982. Detection of ductal dysplasia in mammary outgrowths derived from carcinogen-treated virgin female BALB/c mice. Cancer Res 42: 1753-1760.

Faulkin LJ Jr. 1966. Hyperplastic lesion of the mouse mammary glands after treatment with 3-methylcholanthrese. J Natl Cancer Inst 36: 289-298.

Faulkin LJ Jr, DeOme KB. 1960. Regulation of growth and spacing of gland elements in the mammary fat pad of the C3H mouse. J Natl Cancer Inst 24: 953-969.

Fekete E. 1938. A comparative morphological study of the mammary gland in a high and a low tumor strain of mice. Am J Path 14: 557-578.

Fekete E. 1940. Observations on three functional tests in a high tumor and a low tumor strain of mice. Am J Cancer 38: $234-238$.

Foulds L. 1949. Mammary tumors in hybrid mice: Growth and progression of spontaneous tumors. B J Cancer 3: $345-375$.

Foulds L. 1956. The histologic analysis of mammary tumors in mice. J Natl Cancer Inst 17: 701-801.

Foulds L. 1969. Neoplastic development. Academic Press, New York.

Gardner WU, Strong L, Smith GM. 1939. The mammary glands of mature female mice of strains varying in susceptibility to spontaneous tumor development. Am J Cancer 37: 510-517.

Haaland M. 1911. Spontaneous tumors in mice. In Fourth Scientific Report on the Investigations of the Imperial Cancer Research Fund (ed. E.F. Bashford), pp. 1-113. Imperial Cancer Research Fund, London. 
Huesby RA, Bittner JJ. 1946. A comparative morphological study of the mammary glands with reference to the known factors influencing the development of mammary carcinoma in mice. Cancer Res 6: 240-255.

Hwang SI, Guzman RC, Swanson SM, Nandi S. 1996 Hormone dependent and independent mammary tumor development form $\mathrm{N}$-methyl-N-nitrosourea-treated rat mammary epithelial cell xenografts in the nude mouse: Multiple pathways and H-ras activation. Cancer Lett 101: $123-134$.

Jhappan C, Gallahan D, Stahle C, Chu E, Smith GH, Merlino G, Callahan R. 1992. Expression of an activated notchrelated int-3 transgene interferes with cell differentiation and induces neoplastic transformation in mammary and salivary glands. Genes Dev 6: 345-355.

Jerry DJ, Butel JS, Donehower LA, Paulson EJ, Cochran C, Wiseman RW, Medina D. 1994. Infrequent p53 mutations in 7,12-dimethylbenz[a] anthracene-induced mammary tumors in BALB/c and p53 hemizygous mice. Mol Carcinog 9: 175-183.

Jerry DJ, Kittrell FS, Kuperwasser C, Laucirica R, Dickinson ES, Bonilla PJ, Butel JS, Medina D. 2000. A mammaryspecific model demonstrates the role of the $p 53$ tumor suppressor gene in tumor development. Oncogene 19: 1052-1058.

Jerry DJ, Ozbun MA, Kittrell FS, Lane DP, Medina D, Butel JS. 1993. Mutations in p53 are frequent in the preneoplastic stage of mouse mammary tumor development. Cancer Res 53: 3374-3381.

Jull JW. 1954. The effects of oestrogens and progesterone mammary cancer in mice on the chemical induction of mice of the IF strain. Pathol 68: 547-559.

Kittrell FS, Oborn CJ, Medina D. 1992. Development of mammary preneoplasias in vivofrom mouse mammary epithelial cells in vitro. Cancer Res 52: 1924-1932.

Koch JG, Gu X, Han Y, El-Naggar AK, Olson MV, Medina D, Jerry DJ, Blackburn AC, Peltz G, Amos CL, et al. 2007. Mammary tumor modifiers in BALB/cJ mice heterozygous for p53. Mammalian Genome 18: 300-309.

Kumar R, Medina D, Sukumar S. 1990. Activation of H-ras oncogenes in preneoplastic mouse mammary tissues. Oncogene 5: 1271-1277.

Kuperwasser C, Chavarria T, Wu M, Magrane G, Gray JW, Carey L, Richardson A, Weinberg RA. 2004. Reconstruction of functionally normal and malignant human breast tissues in mice. Proc Natl Acad Sci 101: 4966-4971.

Kuperwasser C, Hurlburt GD, Kittrell FS, Dickinson ES, Laucirica R, Medina D, Naber SP, Jerry DJ. 2000. Development of spontaneous mammary tumors in BALB/c p53 heterozygous mice. A J Pathology 157: 2151-2159.

Lacassagne A. 1932. Apparition de cancers de la mammelle chez la souris male, soumis a des injections de folliculine. CR Acad Sci 195: 630-632.

Lathrop AEC, Loeb L. 1916. Further investigations on the origin of tumors in mice. III. On the part played by internal secretion in the spontaneous development of tumors. J Cancer Res 1: 1-20.

Lydon JP, Ge G, Kittrell FS, Medina D, O’Malley BW. 1999. Murine mammary gland carcinogenesis is critically dependent on progesterone receptor function. Cancer Res 59: 4276-4284.
Lyons MJ, Moore DH 1965. Isolation of the mouse mammary tumor virus: Chemical and morphological studies. J Natl Cancer Inst 35: 549-565.

Maglione JE, McGoldrick ET, Young LJ, Namba R, Gregg JP, Liu L, Moghanaki D, Ellies LG, Borowsky AD, Cardiff RD, et al. 2004. Polyomavirus middle T-induced mammary intraepithelial neoplasia outgrowths: Single origin, divergent evolution and multiple outcomes. Mol Cancer Ther 3: 941-953.

Mallepell S, Krust A, Chambon P, Brisken C. 2006. Paracrine signaling through the epithelial estrogen receptor is required for proliferation and morphogenesis in the mammary gland. Proc Natl Acad Sci U S A 103: 2196-2201.

Medina D. 1973a. Preneoplastic lesions in mouse mammary tumorigenesis. In Methods in cancer research (ed. H. Busch), 7: 3-53. Academic Press, New York.

Medina D. 1973b. Serial transplantation of carcinogen treated nodule outgrowths: III. Dissociation of carcinogen-induced cell variants by dose and chemical structure of carcinogen. J Natl Cancer Inst 50: 1551-1559.

Medina D. 1976. Mammary tumorigenesis in chemical carcinogen-treated mice. VI. Tumor-producing capabilities of mammary dysplasias in BALB/cCRGL mice. J Natl Cancer Inst 57: 1185-1189.

Medina D. 1982. Mammary tumors. In The Mouse in Biomedical Research (ed. H.L. Foster, J.D. Small, J.G. Fox), Vol. 4, 373-396. Academic Press, New York.

Medina D. 2000a. Mouse models for mammary cancer. In Methods in mammary gland biology and breast cancer research (ed. M.M. Ip, B.B. Asch), pp. 3-17. Kluwer Academic Press, New York.

Medina D. 2000b. The preneoplastic phenotype in murine mammary tumorigenesis. J Mammary Gland Biol Neoplasia 5: 393-407.

Medina D. 2002. Biological and molecular characteristics of the premalignant mouse mammary gland. BBA Reviews on Cancer 1603: 1-9.

Medina D, Faulkin LJ Jr, DeOme KB. 1970. The combined effects of 3-methylcholanthrene, MTV, NIV and prolonged hormonal stimulation on the tumor-producing capabilities of the nodule outgrowth line D1. J Natl Cancer Inst 44: 159-165.

Medina D, Butel JS, Socher SH, Miller FL. 1980. Mammary tumorigenesis in 7,12-dimethybenzanthracene-treated C57BL x DBA/2f F1 mice. Cancer Res 40: 368-373.

Medina D, Kittrell FS, Hill J, Shepard A, Thorardson G, Brown P. 2005. Tamoxifen inhibition of estrogen receptor alpha-negative mouse mammary tumorigenesis. Cancer Res 65: 3493-3496.

Medina D, Kittrell FS, Shepard A, Stephens LC, Jiang C, Lu J, Allred DC, McCarthy M, Ullrich RL. 2002. Biological and genetic properties of the p53 null preneoplastic mammary epithelium. FASEB J 16: 881-883.

Medina D, Stephens LC, Bonilla PJ, Hollmann CA, Schwahn D, Kuperwasser C, Jerry DJ, Butel JS, Meyn RE. 1998. Radiation-induced tumorigenesis in preneoplastic mouse mammary glands in vivo: Significance of p53 status and apoptosis. Mol Carcinog 22: 199-207.

Michalides R, van Deemter L, Nusse R, Ropcke G, Boot L. 1978. Involvement of mouse mammary tumor virus in 


\section{Medina}

spontaneous and hormone-induced mammary tumors in low-mammary-tumor mouse strains. J Virol 27: $551-559$.

Mintz B. 1970. Neoplasia and gene activity in allophenic mice. In Genetic Concepts and Neoplasia, 23rd Annual Symposium on Fundamental Cancer Research, M.D. Anderson Hospital and Cancer Institute, pp. 478-517. Williams and Wilkins, Baltimore, MD.

Moraes RC, Zhang X, Harrington N, Fung JY, Wu MF, Hilsenbeck SG, Allred DC, Lewis MT. 2007. Constitutive activation of smoothened (SMO) in mammary glands of transgenic mice leads to increased proliferation, altered differentiation and ductal dysplasia. Development 134: 1231-1242.

Muhlbock O. 1965. Note on a new inbred mouse strain GR/ A. Europ J Cancer 1: 123-124.

Muhlbock O, Boot LM. 1959. Induction of mammary cancer in mice without the mammary tumor agent by isografts of hypophyses. Cancer Res 19: 402-412.

Namba R, Maglione E, Young LJ, Borowsky AD, Cardiff RD, MacLeod CL, Gregg JP. 2004. Molecular characterization of the transition to malignancy in a genetically engineered mouse model of ductal carcinoma in situ. Mol Cancer Res 2: 453-463.

Nandi S, McGrath CM. 1973. Mammary neoplasia in mice. Adv Cancer Res 14: 353-414.

Nicoll CW. 1965. Growth autoregulation and the mammary gland. J Natl Cancer Inst 34: 131-140.

Nusse R, Varmus HE. 1982. Many tumors induced by the mouse mammary tumor virus contain a provirus integrated in the same region of the host genome. Cell 31: 99-109.

Nusse R, Brown A, Papkoff J, Scrambler P, Shackleford G, McMahon A, Moon R, Varmus H. 1991. A new nomenclature for int-1 and related genes: The wnt gene family. Cell 64: 231.

Oberling C, Guerin M. 1954. The role of viruses in the production of cancer. Adv Cancer Res 2: 353-423.

Pitelka DR, Bern HA, Nandi S, DeOme KB. 1964. On the significance of virus-like particles in mammary tissues of C3Hf mice. J Natl Cancer Inst 33: 867-885.

Polyak K. 2007. Breast cancer: Origin and evolution. J Clin Invest 117: 3155-3163.

Ponnaiya B, Cornforth MN, Ullrich RL. 1997. Induction of chromosomal instability in human mammary cells by neutrons and gamma rays. Radiat Res 147: 288-294.

Qing WG, Conti CJ, LaBate M, Johnston D, Slaga TJ, MacLeod MC. 1997. Induction of mammary cancer and lymphoma by multiple, low oral doses of 7,12-dimethylbenz[a] anthracene in SENCAR mice. Carcinogenesis 18: 553-559.

Sass B, Dunn TB. 1979. Classification of mouse mammary tumors in Dunn's miscellaneous group including recently reported types. J Natl Cancer Inst 62: 1287-1293.

Shackleton M, Vaillant F, Simpson KJ, Stingl J, Smyth GK, Asselin-Labat ML, Wu L, Lindeman GJ, Visvader JE. 2006. Generation of a functional mammary gland from a single stem cell. Nature 439: 84-88.

Singh DV, DeOme KB, Bern HA. 1970. Strain differences in response of the mouse mammary gland to hormones in vitro. J Natl Cancer Inst 45: 657-675.

Smith GH, Pauley RJ, Socher SH, Medina D. 1978. Chemical carcinogenesis in $\mathrm{C} 3 \mathrm{H} / \mathrm{StWi}$ mice, a worthwhile experimental model for breast cancer. Cancer Res 38: 4504-4509.

Squartini F, Severi L. 1962. Strain differences in the mammary tumor inducing virus as detected by the characters and behavior of neoplasms. In Tumor Viruses of Murine Origin, (ed. G.E.W. Wolstenholme, M. O'Connor), pp. $82-106$. London.

Staats J. 1966. The laboratory mouse. In Biology of the laboratory mouse (ed. E.L. Green), pp. 1-9. McGraw-Hill, New York.

Strong LC. 1935. The establishment of the C3H inbred strain of mice for the study of spontaneous carcinoma of the mammary gland. Genetics 20: 586-591.

Swanson SM, Guzman RC, Tsukamoto T, Huang TT, Dougherty CD, Nandi S. 1996. N-Ethyl-N-nitrosourea induces mammary cancers in the pituitary-isografted mouse which are histologically and genotypically distinct from those induced by N-methyl-N-nitrosourea. Cancer Lett 102: 159-165.

Ullrich RL, Jernigan MC, Storer JB. 1977. Neutron carcinogenesis. Dose and dose-rate effects in BALB/c mice. Radiat Res 72: 487-498.

van Nie R. 1967. Behavior and morphology of pregnancy responsive mammary tumors in mice. Path Europ 2: 357-373.

Young LJT, Medina D, DeOme KB, Daniel CW. 1971. The influence of host and tissue age on life span and growth rate of serially transplanted mouse mammary gland. Exptl Gerontology 6: 49-56.

Zhang M, Behbod F, Atkinson RL, Landis MD, Kittrell F, Edwards D, Medina D, Tsimelzon A, Hilsenbeck S, Green JE, et al. 2008. Identification of tumor-initiating cells in a p53 null mouse model of breast cancer. Cancer Res 68: 4674-4682. 


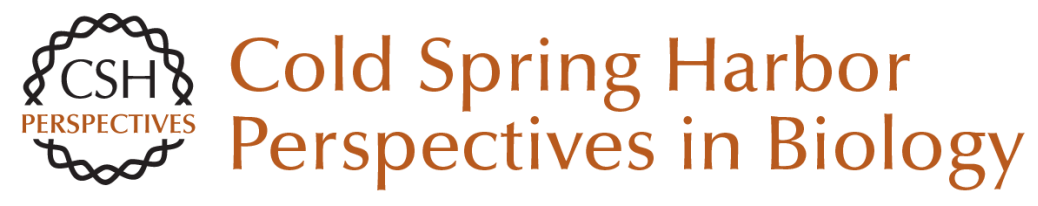

\section{Of Mice and Women: A Short History of Mouse Mammary Cancer Research with an Emphasis on the Paradigms Inspired by the Transplantation Method}

Daniel Medina

Cold Spring Harb Perspect Biol 2010; doi: 10.1101/cshperspect.a004523 originally published online July 14,2010

\section{Subject Collection The Mammary Gland as an Experimental Model}

On the Role of the Microenvironment in Mammary Gland Development and Cancer

Derek Radisky

On Using Functional Genetics to Understand Breast Cancer Biology Kornelia Polyak

On Oncogenes and Tumor Suppressor Genes in the Mammary Gland

Rushika M. Perera and Nabeel Bardeesy

On Leukocytes in Mammary Development and Cancer

Cyrus M. Ghajar

On Chromatin Remodeling in Mammary Gland

Differentiation and Breast Tumorigenesis Kornelia Polyak

On Hormone Action in the Mammary Gland J.M. Rosen

TGF- $\beta$ Biology in Mammary Development and Breast Cancer

Harold Moses and Mary Helen Barcellos-Hoff
On How Mammary Gland Reprogramming

Metalloproteinases Couple Form with Function Bonnie F. Sloane

On Molecular Mechanisms Guiding Embryonic Mammary Gland Development Gertraud W. Robinson

On Stem Cells in the Human Breast Mark A. LaBarge

On Murine Mammary Epithelial Stem Cells:

Discovery, Function, and Current Status Jeffrey M. Rosen

On In Vivo Imaging in Cancer David Piwnica-Worms

Choosing a Mouse Model: Experimental Biology in Context--The Utility and Limitations of Mouse Models of Breast Cancer Alexander D. Borowsky

Mammary Gland ECM Remodeling, Stiffness, and Mechanosignaling in Normal Development and Tumor Progression

Pepper Schedin and Patricia J. Keely

For additional articles in this collection, see http://cshperspectives.cshlp.org/cgi/collection/

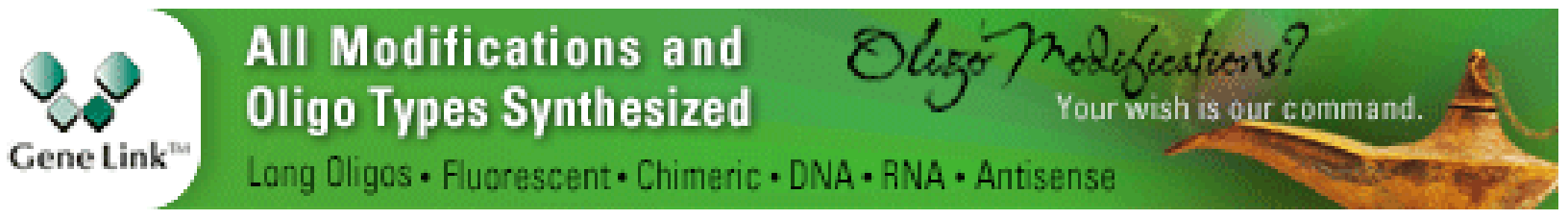


A Compendium of the Mouse Mammary Tumor Biologist: From the Initial Observations in the House Mouse to the Development of Genetically Engineered Mice

Robert D. Cardiff and Nicholas Kenney
Molecular Mechanisms Guiding Embryonic Mammary Gland Development

Pamela Cowin and John Wysolmerski

For additional articles in this collection, see http://cshperspectives.cshlp.org/cgi/collection/

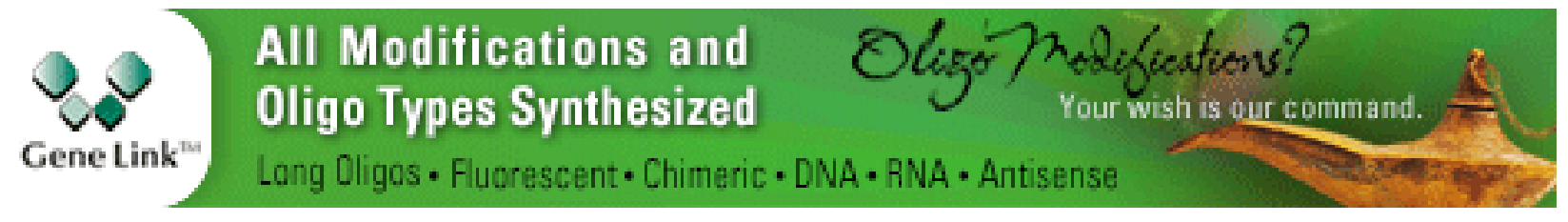

Copyright @ 2010 Cold Spring Harbor Laboratory Press; all rights reserved 